future holds. Plague is only one of several ancient infections lingering on the margins of human well-being. Tuberculosis and hepatitis- $\mathrm{B}$ are more prevalent and more serious problems of public health, as are malaria and trypanosome disease. But plague evokes atavistic fears even in comfortable Europe, where it has not been heard of since the seventeenth century. Curiously, there are even pockets of plague among rodents in the American southwest from which people occasionally die. Eradication is notoriously difficult when there is a reservoir of infection among a wild animal population, but that is no reason for not finding out. Instead of killing rodents as in the past few weeks, the people of India might be better employed on trapping them so that the prevalence of the plague bacterium in the wild might be estimated more accurately.

\section{Magellan's success}

The spacecraft Magellan, due to end its sojourn around Venus on 11 October, is a success for NASA.

THE Magellan mission to Venus, ended by the deliberate extinction of the spacecraft on 11 October, has had plenty to say both about Venus and the proper conduct of space science. At the most prosaic level, the $\$ 900$-million probe has successfully fulfilled its mission by sending radar signals through the planet's dense atmosphere, returning to Earth the most accurate geological map of any planet. More generally, the four-year mission is vivid testimony to people's resourcefulness. Cut back under the Reagan administration, the Magellan mission had to make do with a far simpler single-instrument probe than the National Aeronautics and Space Administration (NASA) had designed, yet it has proved to be of more use to more disciplines of science than anybody expected. The policy-makers, of course, may not be pleased with the observation of one project engineer that Magellan has demonstrated "the extraordinary variety of science that can be extracted from a single-string fiddle".

But Magellan was not exactly cheap. Its survival in the harsh conditions of an oscillation each 90-minute orbit between extremes of hot and cold has proved the worth of proper systems engineering. Ground controllers, for example, have been able to simulate the real effect of every command sent to Magellan throughout the mission by the use of a dummy probe on Earth. The advocates of smaller, faster and cheaper space exploration do not always bother with such niceties. That is one reason why their great hope - Clementine - knocked itself out in May. (The infuriating silence of the missing Mars Observer since 21 August 1993 is something else again.)

Even on its planned demise this week, Magellan was expected to glean extra information. The plan was to lower the orbit gently, causing a tendency for the probe to spin, and then to measure the viscosity of the atmosphere of Venus by the reaction of the booster motors as they adjust to prevent rotation - a memorable null experiment if ever there was one. That should be a guide to atmospheric composition. It is also an object lesson in getting out while the going's good: to have let the probe struggle on until it failed would yield little science and plenty of bad publicity.

But perhaps the most impressive feature of the Magellan project is not its success as an engineering project, or even its prodigious output of scientific data, but the way in which data have been disseminated. Magellan's maps are already available to most of us on the Internet. Failing that, they can be bought on compact disc. Thus the data from the mission are not the plaything of some conclave, but are available to everyone to use. School science will have a field day when teachers tumble to what there is. In space science as elsewhere, that is the shape of things to come.

And the bad news? Magellan burned up leaves NASA's mispriorities even more exposed than before. A diminishing number of financially pressed but scientifically interesting planetary missions stand beside the vastly expensive manned space programme which masquerades as science but whose actual purpose lies elsewhere. Sadly, there seems not the slightest chance that NASA will learn from Magellan where to look for affordable success, and that it will invest more energy (and money) in the planetary programme at the expense of what is fast coming to seem the most expensive public works programme ever: space-station Freedom and its infrastructure.

\section{Natural conservation}

\section{Raptors, and falcons in particular, may have forfeited their right to conservation.}

EVERYBODY knows that nature is red in tooth and claw, but it can go too far. There will be consternation among readers of the London Times at the report (10 October) of recent happenings on the Ile Aux Aigrettes, off Mauritius. The island is one of the centres at which the Jersey Wildlife Preservation Trust, supported by the naturalist and writer Gerald Durrell, is seeking to nurse back to viability endangered bird species, notably the Mauritius kestrel and the pink pigeon once also indigenous to Mauritius. But now the unthinkable has happened. With both species now numerous enough to be returned to the wild after a captive breeding programme, it appears that a kestrel has taken a fledgling pigeon from its nest. The pigeon is by now presumed eaten.

Savagery of this kind puts conservationists everywhere in a fix. What purpose can be served by rescuing pigeons from the endangered list if they are then to be eaten by onceendangered falcons? Sadly, it is hard to see how this practice, instinctive though it may be, can easily be ended. Even if adult kestrels were conditioned against the consumption of pigeons before being returned to the wild, their offspring (absent Lamarck) would probably be less discriminating. For the long run, the outlook is even more gloomy. The small size of the population of surviving pigeons before their conservation was taken in hand may itself be a monument to the past activities of the raptors. There are hard choices to be made on the Ile Aux Aigrettes. 